\title{
The Synthesis of CuO-Based Nanofluids as a Cooling Media:
}

\author{
A Review \\ A Esmawan, G Antarnusa*, I H Lilmuttaqin, M A Ramadhan, N Chusniah \\ Department of Physics Education \\ Universitas Sultan Ageng Tirtayasa \\ Banten, Indonesia \\ *ganesha.antarnusa@untirta.ac.id
}

\begin{abstract}
Nanofluids have received significant attention due to their increased thermal characteristics. This increase was due to the addition of nanoparticles in the basic fluid. This research uses literature study method. Based on the literature study that has been done, the thermal conductivity of water and $\mathrm{CuO}$ is high. However, the value of the thermal conductivity of water$\mathrm{CuO}$ nanofluids also varies according to experiments conducted by Das et al., Sahooli et al., and Micali et al. This can occur due to several factors such as the size of the nanoparticles, agglomeration, pH value, and others. With this high thermal conductivity value, water- $\mathrm{CuO}$ nanofluid can be used as a cooling medium.
\end{abstract}

Keywords-CuO-based nanofluids, cooling media, review

\section{INTRODUCTION}

Nanofluids are fluids that contain nanometer-sized $(<100$ nm) particles, called nanoparticles. This fluid is a colloidal suspension engineered from nanoparticles in the base fluid. In recent years, nanofluids have received significant attention due to their increased thermal characteristics. This increase was due to the addition of nanoparticles in the basic fluid. The type of nanoparticles is one of the factors to obtain high thermal conductivity. Copper oxide $(\mathrm{CuO})$ is included in the oxide nanoparticles, these nanoparticles are used because they have high thermal conductivity. so that the nanofluids synthesized with $\mathrm{CuO}$ nanoparticles also have better conductivity compared to other oxide nanofluids [1]. To make nanofluids more stable, you can adjust the $\mathrm{pH}$ (electrostatic stabilization) and add a dispersant or surfactant (steric stabilization) [2,3]. There are two methods for preparation in the manufacture of nanofluids: the one-step method and the two-step method.

The process of cooling media, which are absorbing heat and transferring heat to the fluid, functions as a coolant. Cooling efficiency using nanofluids is influenced by specific heat density, thermal conductivity, and various other heat transfer properties [4]. Of these, the thermal conductivity of nanofluids is the most complex and the most important for many applications [5]. Such as electronic cooling media, nuclear reactor coolers, car radiator water and various other applications.

Sahooli, et al. synthesized CuO-ethylene glycol with the addition of PVP as a surfactant. As a result, the addition of surfactants increases the stability and nanofluids thermal conductivity [6]. Septiadi, et al. conducted research on the characterization of the thermal conductivity of oxide nanofluids. The result is that the thermal conductivity of $\mathrm{CuO}$ air is higher than that of $\mathrm{Al} 2 \mathrm{O} 3$-air and $\mathrm{TiO} 2$-air nanofluids at both low and high-volume fractions [7]. Noor et al. discussed the synthesis of egg white mediated $\mathrm{CuO}$-based nanofluids for ethanol distillation applications. From these results, it was found that the addition of nanoparticle levels influenced the increase in the thermal conductivity of the nanofluids [8]. The $\mathrm{CuO}$ nanoparticles thermal conductivity $\left(\mathrm{k} \_\mathrm{p}\right)$ is $18 \mathrm{~W} / \mathrm{mk}$, and the thermal conductivity of water (k_f) is $0.613 \mathrm{~W} / \mathrm{mk}$ [9]. In this paper we report the thermal conductivity of water-CuO nanofluids in existing experiments and several theories with a volume fraction of $1 \%-4 \%$.

\section{PREPARATION NANOFLUIDS}

The synthesis Nanofluid is a colloid suspension which has a particle size between 1-100 $\mathrm{nm}$ which is dispersed in the base fluid. The method in preparing the manufacture of nanofluids can be done in two ways, one-step method and two-step method.

\section{A. One-Step Method}

The one-step method is a method that directly combines the manufacture of nanoparticles with nanofluid synthesis [10]. The one-step method is also divided into two, namely the physical method and the chemical method. Physical methods include vapor deposition, laser ablation, and submerged arc. Meanwhile, chemical methods use chemical reactions for the manufacture of nanofluids. The advantages of the one-step synthesis method are that the agglomeration of the nanoparticles is reduced, and it is more economical. 
1) Physical methods: Vapor deposition, a method developed by Choi, is the most common method to use. The principle can be seen in Figure 1. On the vessel wall, this thin layer of base liquid is formed using the centrifugal force of a rotating disk. In the process, the raw material is heated and evaporated in a resistive heated container. Then, the vapor is condensed into nano-sized particles when it meets the cold base fluid. So that the nanofluid was obtained [11]. Lee et al. prepared ethylene glycol-TiO2 nanofluids using the pulsed wire evaporation method [12]. The results showed that the thermal conductivity of the nanofluids increased the volume concentration of the nanoparticles but there was no increase in temperature variations.

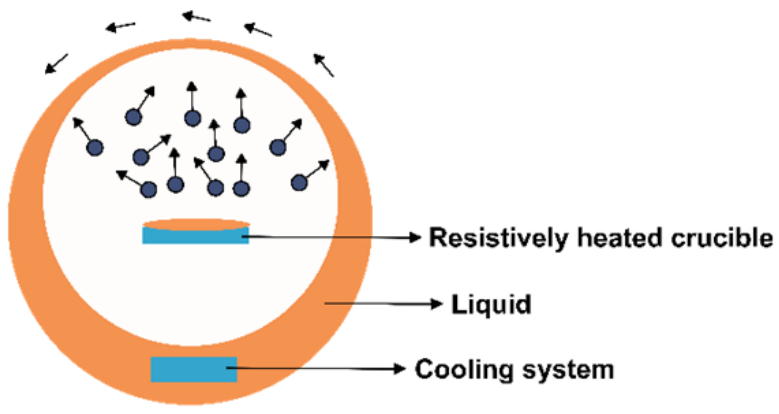

Fig. 1. Schematic diagram of the Vapor deposition method [13].

Laser Ablation Method, this method consists in the synthesis of nanoparticles during the interaction of a laser pulse with a solid target surface in a liquid environment. There are several promising advantages of laser ablation in liquids such as simplicity of the technique and rapidity compared to other methods [14]. Figure 2 shows the experimental equipment for the PLAL method. Lee et al. presented the PLAL method in the manufacture of $\mathrm{CuO} / \mathrm{DIW}$ nanofluids with the aim of controlling the morphology of the nanoparticles [12].

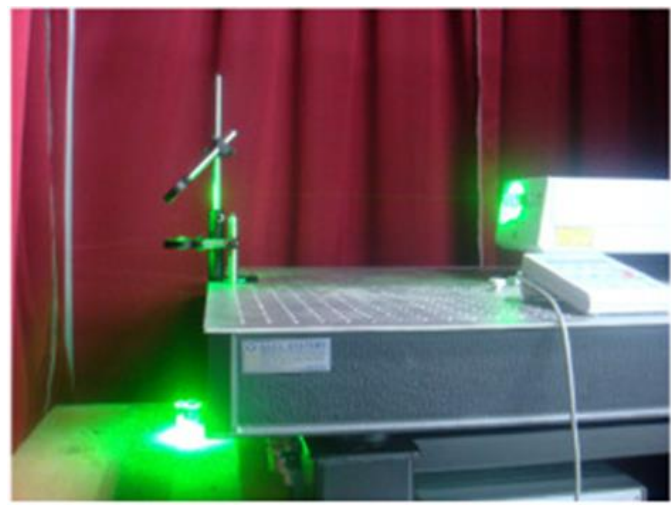

Fig. 2. Experimental equipment for the PLAL method [15].

Submerged Arc Nanoparticle Synthesis System (SANSS) Method, The SANSS method involves the evaporation of bulk metal by Submerged Arc produced by high temperatures. Dielectric fluids are used to immediately quench evaporating metals to suppress the growth of nanoparticles. Then, centrifugation and sedimentation were carried out on the nanoparticle suspension condensed in the dielectric fluid. Then from this process to produce nanofluids [16]. Lo et al. presented the SANSS method to prepare silver nanofluids (figure 3 ). The result with this method can reduce the particle size to the nanoscale [17].

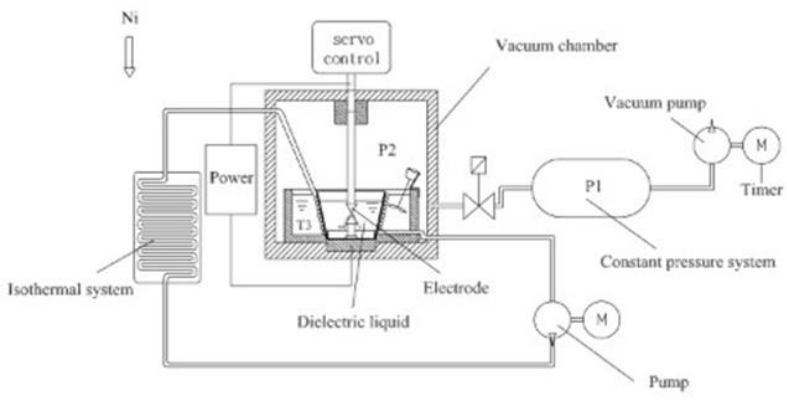

Fig. 3. Schematic diagram of the SANSS [17]

2) Chemical methods: Chemical methods have advantages in terms of controlling particle size, reducing agglomeration, and can produce nanofluids on a large scale $[17,18]$. Zhu et al. has conducted research using microwave irradiation in a onestep chemical method to prepare copper nanofluids by reducing $\mathrm{CuSO} 4.5 \mathrm{H} 2 \mathrm{O}$ with $\mathrm{NaH} 2 \mathrm{PO} 2 . \mathrm{H} 2 \mathrm{O}$ to ethylene glycol [19]. The results showed that the use of microwave irradiation and the addition of $\mathrm{NaH} 2 \mathrm{PO} 2 . \mathrm{H} 2 \mathrm{O}$ were two significant factors that influenced the reaction rate and properties of $\mathrm{Cu}$ nanofluids. Shenoy et al. reported on the synthesis of copper oxide nanofluids by a one-step chemical method with the addition of polyvinyl pyrrolidone (PVP). The results of the study increased the stability of the nanofluid produced for about 9 weeks [20].

\section{B. Two-Step Method}

The two-step method is the method most widely used for the preparation of nanofluids. In this method, nanoparticles must be prepared in advance through a physical or chemical synthesis process, such as: co-precipitation [21], sol-gel, spray pyrolysis and others. The most popular and effective two-step method for preparing long-stable, homogeneously dispersed nanofluids is ultrasonication. This method utilizes vibrations with ultrasonic waves. Various parameters affect the dispersion of nanofluids using different treatments such as the type of ultrasonication, time of ultrasonication, power of ultrasonication and so on. The type of ultrasonication consists of direct ultrasonication (ultrasonic horn/probe) or indirect ultrasonication (ultrasonic bath) [22] (figure 4). 


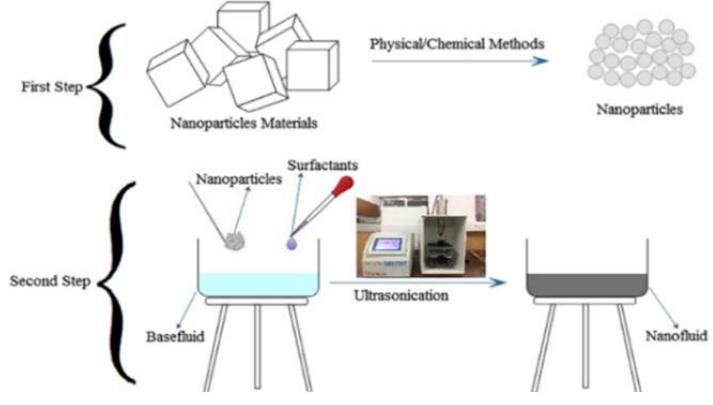

Fig. 4. Two-step nanofluid preparation [23].

\section{Theoritical and Experimental Nanofluid Thermal Conductivity}

One of the well-known theoretical models that can be used to predict the thermal conductivity of nanofluids is the investigation phase of Maxwell's Model [24]. This model is suitable for particles with a low volume fraction that have a spherical shape. The equation is as follows:

$\frac{k_{n f}}{k_{b f}}=\frac{k_{p}+2 k_{b f}+2 \varphi\left(k_{p}-k_{b f}\right)}{k p+2 k_{b f}-\varphi\left(k_{p}-k_{b f}\right)}$

Where $k_{n f}$ is the nanofluid thermal conductivity, $k_{p}$ is the thermal conductivity particles, $k_{b f}$ is the thermal conductivity base fluid, and $\varphi$ is the volume fraction.

$\frac{k_{n f}}{k_{b f}}=\frac{k_{p}+2 k_{b f}+2\left(k_{p}-k_{b f}\right)(1+\beta)^{3} \varphi}{k_{p}+2 k_{b f}-2\left(k_{p}-k_{b f}\right)(1-\beta)^{3} \varphi}$

Based on the above equation, $\beta=0.1$ is used to calculate the effective thermal conductivity of the nanofluid. Which $\beta$ is the ratio of the thickness of the nanofluid layer to the particle radius.

Timofeeva et al. introduced a new model for calculating the thermal conductivity of nanofluids as follows $[25,26]$ :

$\frac{k_{n f}}{k_{b f}}=(1+3 \varphi)$

From Equations (1), (2) and (3), the nanofluid effective thermal conductivity has a relationship to the volume fraction in Figure 5.

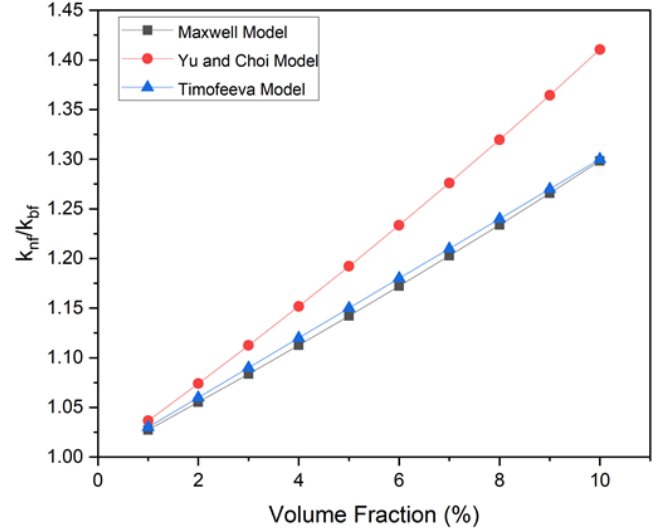

Fig. 5. Effective thermal conductivity of water-CuO nanoparticles.

This thermal conductivity was obtained from experiments of Das et al., Sahooli et al., and Micali [14,27,28]. The effective thermal conductivity $\left(k_{n f} / k_{b f}\right)$ is obtained as in table 1 .

TABLE I. EFFECTIVE THERMAL CONDUCTIVITY FOR WATER-CUO NANOFLUIDS FROM SEVERAL EXPERIMENTS

\begin{tabular}{|l|l|l|}
\hline \multicolumn{1}{|c|}{ Author } & Volume Fraction (\%) & $k_{\mathrm{nf}} / k_{\mathrm{bf}}$ \\
\hline Das et al. (2003) & $1-4$ & $1-1,14$ \\
\hline Sahooli et al. (2012) & $1-6$ & $1-1,17$ \\
\hline Micali et al. (2018) & $1-4$ & $1-1,17$ \\
\hline
\end{tabular}

The effective thermal conductivity with increasing water$\mathrm{CuO}$ volume fraction in the existing experiments has the same tendency when compared to the Maxwell model, Yu and Choi model, and Timofeeva model. As can be seen in Figure 6. The effective thermal conductivity between the thermal conductivity model and the experimental results increases with increasing volume fraction.

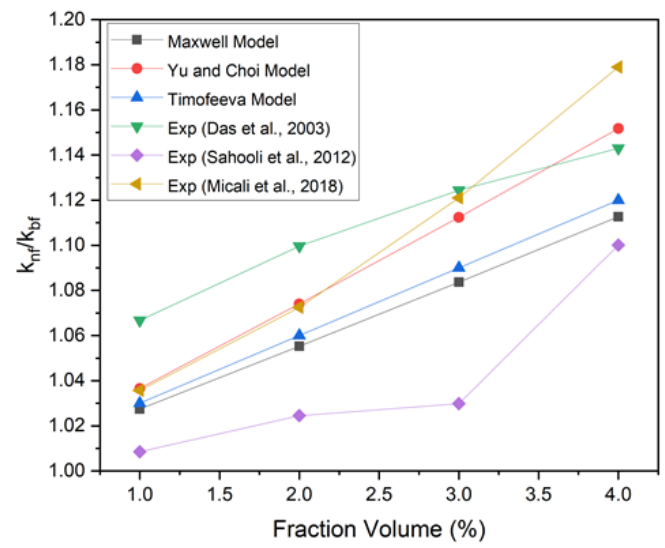

Fig. 6. Graph of the effective thermal conductivity of Water-CuO with respect to volume fraction.

In the Sahooli experiment there was the addition of the surfactant Polyvinyl Pyrrolidone (PVP) in the Water-CuO synthesis. The addition of surfactants can increase the thermal 
conductivity of the nanofluids and make the nanofluids more stable [29]. However, it appears that the effective thermal conductivity is lower than that of Air-CuO nanofluids without the addition of surfactants. This can be caused by many factors such as: nanoparticle size, agglomeration, $\mathrm{pH}$ value, and others.

\section{NANOFLIUDS APPLICATION}

Nanofluids in theory have a high thermal conductivity which can be used as a cooling medium. According to Ramadhan et al., nanofluids can be used as a cooling fluid for electronic devices such as to cool semiconductors on a computer CPU so that the chip can last a long time when operated. This nanofluid can also be applied as a cooling fluid in nuclear reactors [30]. The use of nanofluids aims to increase the heat transfer that occurs in the core of a nuclear reactor, which causes heat from nuclear fission to be taken and converted into a steam generator or heat exchanger which is then streamed to turbines and generators.

\section{CONCLUSION}

The results of literature studies that have been conducted regarding the thermal conductivity of water- $\mathrm{CuO}$ are based on theory and experiment. Each of them shows a significant increase in thermal conductivity at low volume fractions. Based on the model results and the experimental results of thermal conductivity, the effective thermal conductivity increases with increasing volume fraction. Therefore, this increase in thermal conductivity can be used as a cooling medium.

\section{ACKNOWLEDGMENTS} 2020

This research was funded by Direktorat Belmawa-Dikti

\section{REFERENCES}

[1] B. Chitra and K.S. Kumar, "Heat transfer enhancement using single base and double base nanofluids," Journal of Molecular Liquids, vol. 221, pp. 1128-1132, 2016

[2] P. Nurhidayati, D.G. Syarif and H. Aliah, "Pengaruh Konsentrasi Polietilen Glikol (Peg) Terhadap Karakteristik Nano Fluida AirAlumina,” Jurnal Sains Materi Indonesia, vol. 17, no. (2), pp. 77, 2018.

[3] G. Antarnusa and E. Suharyadi, "A synthesis of polyethylene glycol (PEG)-coated magnetite $\mathrm{Fe} 3 \mathrm{O} 4$ nanoparticles and their characteristics for enhancement of biosensor," Materials Research Express, vol. 7, no. (5), pp. 056103, 2020

[4] R.R. Meena, S.H. Chaki, A.J. Khimani and M.P. Deshpande, "Synthesis, characterization of $\mathrm{CuO}$ nanostrips and ultrasonic study of $\mathrm{CuO}$ transformer oil nanofluids," Materials Research Express, vol. 6, no. (4), pp. 045051, 2019

[5] C. Kleinstreuer and Y. Feng, "Experimental and theoretical studies of nanofluid thermal conductivity enhancement: a review," Nanoscale research letters, vol. 6, no. (1), pp. 1-13, 2011.

[6] M. Sahooli and S. Sabbaghi, "CuO nanofluids: the synthesis and investigation of stability and thermal conductivity," Journal of Nanofluids, vol. 1, no. (2), pp. 155-160, 2012.
[7] W.N. Septiadi, N. Putra and R. Saleh, "Karakterisasi Konduktivitas Termal Nanofluida Oksida Berbasis Fluida Dasar H 2 O," Energi dan Manufaktur, vol. 8, pp. 111-230, 2015.

[8] A. Noor, J. Evi, A.D. Safitri, R.A. Rafsanjani and Y. Tiandho, "Stannum: Jurnal Sains dan Terapan Kimia, vol. 2, no. (1), pp. 7-12, 2020

[9] D. Ramasamy, R.S. Sudhakara, T. Ramachandran and S. Gunasekharan "International Journal of Innovative Technology and Exploring Engineering, vol. 8, no. (2), pp. 34-39, 2018.

[10] S.K. Sharma and S.M. Gupta, "Preparation and evaluation of stable nanofluids for heat transfer application: a review," Experimental Thermal and Fluid Science, vol. 79, pp. 202-212, 2016.

[11] G.J. Lee, C.K. Kim, M.K. Lee and C.K. Rhee, "Characterization of ethylene glycol based Tio.,” Rev. Adv. Mater. Sci, vol. 28, pp. 126-129, 2011.

[12] N. Zhu, H. Ji, P. Yu, J. Niu, M.U. Farooq, M.W. Akram and X. Niu, "Surface modification of magnetic iron oxide nanoparticles," Nanomaterials, vol. 8, no. (10), pp. 810, 2018.

[13] L. Kong, J. Sun and Y. Bao, "Preparation, characterization and tribological mechanism of nanofluids," Rsc Advances, vol. 7, no. (21) pp. 12599-12609, 2017.

[14] A. Riahi, S. Khamlich, M. Balghouthi, T. Khamliche, T.B. Doyle, W. Dimassi and M. Maaza, "Study of thermal conductivity of synthesized Al2O3-water nanofluid by pulsed laser ablation in liquid," Journal of Molecular Liquids, vol. 304, pp. 112694, 2020.

[15] C.H. Lo, T.T. Tsung and L.C. Chen, "Shape-controlled synthesis of Cubased nanofluid using submerged arc nanoparticle synthesis system (SANSS)," Journal of Crystal Growth, vol. 277, no. (1-4), pp. 636-642, 2005

[16] C.H. Lo, T.T. Tsung, H.M. Lin, "Preparation of silver nanofluid by the submerged arc nanoparticle synthesis system (SANSS)," Journal of Alloys and Compounds, vol. 434, pp. 659-662, 2007.

[17] H.T. Zhu, Y.S. Lin and Y.S. Yin, "A novel one-step chemical method for preparation of copper nanofluids," Journal of colloid and interface science, vol. 277, no. (1), pp. 100-103, 2004

[18] P.E. Swastika, G. Antarnusa, E. Suharyadi, T. Kato and S. Iwata, "Biomolecule detection using wheatstone bridge giant magnetoresistance (GMR) sensors based on $\mathrm{CoFeB}$ spin-valve thin film," Journal of Physics: Conference Series, vol. 1011, no. 1, pp. 012060. IOP Publishing, 2018.

[19] H. Zhu, D. Han, Z. Meng, D. Wu and C. Zhang, "Preparation and thermal conductivity of $\mathrm{CuO}$ nanofluid via a wet chemical method," Nanoscale research letters, vol. 6, no. (1), pp. 1-6, 2011.

[20] U.S. Shenoy and A.N. Shetty, "A simple single-step approach towards synthesis of nanofluids containing cuboctahedral cuprous oxide particles using glucose reduction," Frontiers of Materials Science, vol. 12, no. (1), pp. 74-82, 2018

[21] G. Antarnusa, P.E. Swastika and E. Suharyadi, "Wheatstone bridgegiant magnetoresistance (GMR) sensors based on $\mathrm{Co} / \mathrm{Cu}$ multilayers for bio-detection applications," In Journal of Physics: Conference Series, vol. 1011, no. 1, pp. 012061. IOP Publishing, 2018

[22] A. Asadi, F. Pourfattah, I.M. Szilágyi, M. Afrand, G. Żyła, H.S. Ahn, and O. Mahian, "Effect of sonication characteristics on stability, thermophysical properties, and heat transfer of nanofluids: A comprehensive review," Ultrasonics sonochemistry, vol. 58, pp. 104701 , 2019.

[23] A. Kumar and S. Subudhi, "Preparation, characterization and hea transfer analysis of nanofluids used for engine cooling," Applied Thermal Engineering, vol. 160, pp. 114092, 2019.

[24] A.A. Nadooshan, Phys. E (Amsterdam, Neth.), vol. 87, pp. 15-19, 2017.

[25] A. Tongkratoke, A. Pramuanjaroenkij, A. Chaengbamrung and S. Kakac, "The permeability effects of copper-nanofluid flow with using the porous media model," Proceedings of CHT-15. 6 th International Symposium on ADVANCES IN COMPUTATIONAL HEAT TRANSFER. Begel House Inc, 2015. 
[26] E.V. Timofeeva, A.N. Gavrilov, J.M. McCloskey, Y.V. Tolmachev, S. Sprunt, L.M. Lopatina and J.V. Selinger, "Thermal conductivity and particle agglomeration in alumina nanofluids: experiment and theory," Physical Review E, vol. 76, no. (6), pp. 061203, 2007.

[27] S.K. Das, N. Putra, P. Thiesen and W. Roetzel, "Temperature dependence of thermal conductivity enhancement for nanofluids," J. Heat Transfer, vol. 125, no. (4), pp. 567-574, 2003
[28] F. Micali, M. Milanese, G. Colangelo and A. de Risi, "Experimental investigation on 4-strokes biodiesel engine cooling system based on nanofluid," Renewable energy, vol. 125, pp. 319-326, 2018.

[29] M. Nauva, W.N. Putra and S. Harjanto, TECHNOPEX ITI, pp. 226-229, 2018

[30] A.I. Ramadhan, E. Diniardi and C. Sutowo, Simposium Nasional Teknologi Terapan (SNTT) I 2013 M36-M40, 2013. 